\title{
Tandem duplication of the terminal band of the long arm of chromosome 7 (dir dup (7) $(\mathrm{q} 36 \rightarrow \mathrm{qter})$ )
}

Ram S Verma, Robert A Conte, Jean H Pitter

\begin{abstract}
We report on a new case of a single band duplication of the long arm of chromosome 7 , dir dup (7)(q36 $\rightarrow$ qter). The major manifestations are developmental delay (particularly speech), frontal bossing, macrocrania, and constant drooling. When compared with other cases involving a 7q duplication of various segments, our patient has a few minor anomalies. This case illustrates the genotype/phenotype correlation in a child with a single band duplication which has resulted in duplication of 7 q36 $\rightarrow$ qter. A tabulation of reported cases with duplication of various segments of $7 q$ is provided, which may serve as an aid for clinicians.
\end{abstract}

In recent years, numerous attempts have been made to correlate syndrome manifestation with specific chromosome segments. Delineation of a distinct syndrome resulting from duplication of $7 q$ was first reported by Vogel. ${ }^{1}$ During the past few decades, several reports have appeared describing the clinical consequences associated with duplications of various segments of $7 \mathrm{q}^{2}{ }^{2}$ The longest reported duplicated segment is $7 \mathrm{q} 21 \rightarrow$ qter, while the smallest is $7 \mathrm{q} 33 \rightarrow \mathrm{qter}$. It has been suggested that at least three possible distinct clinical syndromes can be established, based on three segments corresponding to regions $\mathrm{q} 21$ or $22 \rightarrow$ q31, q31 $\rightarrow$ qter, and q32 $\rightarrow$ qter. ${ }^{3}$ Patients with duplication of $7 \mathrm{q} 21$ or $22 \rightarrow \mathrm{q} 31$ are more severely abnormal than those with duplications of the other two segments. We present a case where the smallest portion of the long arm of chromosome 7 (q36 $\rightarrow$ qter) is tandemly duplicated with a few clinical manifestations. We suggest that these manifestations are associated with this region. A table listing the anomalies associated with duplications of various regions of $7 \mathrm{q}$ is also provided.

\section{Case report}

A $3 \frac{1}{2}$ year old boy was referred for developmental delay, particularly speech. He was delivered at term to a 41 year old mother with no prenatal or postnatal complications. His mother gave a history of mild delay in gross motor development and of ADL skills with significant delay in speech and language.

On physical examination he had frontal bossing and macrocrania. Neurologically, he had a short attention span, poor socialisation, and unintelligible speech with delayed graphomotor skills. Constant drooling was noted. There were no cranial nerve abnormalities. Tone was slightly increased in the left Achilles tendon with a few beats of ankle clonus. However, deep tendon reflexes were normal and there were no cerebellar abnormalities or sensory deficits.

He was first referred to rule out fragile $\mathrm{X}$ in his peripheral blood and was found to be negative. However, additional genetic material on the long arm of chromosome 7 was noted. The aberration occurred de novo as the parents are cytogenetically normal. A tandem duplication seems the most likely explanation and is compatible with the banding pattern of band $7 q 36 \rightarrow$ qter (figure). The cytogenetic findings of this patient can be described as $46, X Y$,dir $\operatorname{dup}(7)(q 36 \rightarrow q t e r)$. The parents refused photographic documentation, and the patient has been impossible to trace for dermatoglyphic evaluation. A cell line is not available from this patient.

\section{Discussion}

A number of reports describing duplication of the long arm of chromosome 7 (7q) have appeared since 1972. These reports suggested that the duplication of various segments can be classified into at least three distinct syndromes relating to $\mathrm{q} 21$ or $\mathrm{q} 22 \rightarrow \mathrm{q} 31, \mathrm{q} 31 \rightarrow \mathrm{qter}$, and q32 $\rightarrow$ qter. The most frequent type of aberration resulting in duplication is $7 \mathrm{q} 32 \rightarrow \mathrm{qter}{ }^{4}$ The clinical findings observed in previous cases are summarised in the table. Obviously, the severity of the clinical manifestations is related to the size of the chromosomal segment involved. However, a few exceptions have been observed. For example, cleft palate was reported in a case of dup $7 \mathrm{q} 22$ to $\mathrm{q} 31 \rightarrow \mathrm{qter}^{2}$ and renal microcysts and retardation were seen in most cases. ${ }^{5}$ All patients with duplication of 7q31 $\rightarrow$ qter died soon after birth, while those with other types of aberration lived over one year. ${ }^{3}$

Various attempts have been made to describe a so called 'dup $7 \mathrm{q}$ syndrome'. It is debatable whether it can be identified as a distinct syndrome before cytogenetic evaluation because of the highly variable physical characteristics. The present case was referred to rule out fragile X syndrome. Recently, Bartsch et $a l^{5}$ suggested that "a recognizable phenotype may result in some patients with partial duplication (7q), even if the duplication is small". However, this is not the case in our patient, who has minimal clinical features and 
Clinical manifestations associated with various segments of chromosome $7 q .^{*}$

\begin{tabular}{|c|c|c|c|c|c|c|c|c|c|c|}
\hline Features & $\begin{array}{l}7 \mathrm{q} 21 \\
\rightarrow \text { qter }\end{array}$ & $\underset{\rightarrow \mathrm{qter}}{7 \mathrm{q} 21+\mathrm{q} 22}$ & $\begin{array}{l}7 \mathrm{q} 22 \\
\rightarrow \mathrm{q} 31\end{array}$ & $\underset{\rightarrow \mathrm{qter}}{7 \mathrm{q} 22}$ & $\underset{\rightarrow \mathrm{qter}}{7 \mathrm{q} 31}$ & $\underset{\rightarrow \text { qter }}{7 \mathrm{q} 32}$ & $\begin{array}{l}7 q 33+q 34 \\
+q 35 \rightarrow q \text { ter }\end{array}$ & $\begin{array}{l}7 \mathrm{q} 34 \\
\rightarrow \mathrm{qter}\end{array}$ & $\begin{array}{l}\text { 7q35 } \\
\rightarrow \text { qter }\end{array}$ & $\begin{array}{l}\text { Present } \\
\text { case }\end{array}$ \\
\hline Microcephaly & $2 / 2$ & $3 / 5$ & $2 / 3$ & $1 / 1$ & $4 / 6$ & $7 / 16$ & $1 / 3$ & $0 / 1$ & $1 / 1$ & + \\
\hline Wide open fontanelles & $1 / 2$ & $2 / 5$ & $0 / 3$ & $1 / 1$ & 46 & $7 / 13$ & $1 / 2$ & $0 / 1$ & $1 / 1$ & - \\
\hline Frontal bossing & $0 / 2$ & $2 / 5$ & $2 / 3$ & $1 / 1$ & $4 / 6$ & $7 / 16$ & $1 / 3$ & $0 / 1$ & $1 / 1$ & + \\
\hline Prominent occipital bones & $1 / 2$ & $3 / 5$ & $0 / 3$ & $1 / 1$ & $3 / 6$ & $1 / 16$ & $1 / 3$ & $0 / 1$ & $0 / 1$ & - \\
\hline Small palpebral fissures & $2 / 2$ & $3 / 5$ & $2 / 3$ & $0 / 1$ & 2,6 & $3 / 16$ & $1 / 3$ & $0 / 1$ & $1 / 1$ & - \\
\hline Hypertelorism & $2 / 2$ & $4 / 5$ & $2 / 3$ & $1 / 1$ & $2 / 6$ & $4 / 16$ & $0 / 3$ & $0 / 1$ & 01 & - \\
\hline Epicanthic folds & $0 / 2$ & $0 / 5$ & $2 / 3$ & $0 / 1$ & $1 / 6$ & $8 / 16$ & $1 / 3$ & $0 / 1$ & $1 / 1$ & - \\
\hline Downward slanting eyes & $2 / 2$ & $3 / 5$ & $0 / 3$ & $1 / 1$ & $2 / 6$ & $5 / 16$ & $2 / 4$ & 11 & $0 / 1$ & - \\
\hline Strabismus & NR & $0 / 5$ & $3 / 3$ & NR & $1 / 6$ & $4 / 16$ & $1 / 3$ & NR & NR & - \\
\hline Small nose & $2 / 2$ & $3 / 5$ & $1 / 3$ & $1 / 1$ & $2 / 6$ & $6 / 16$ & $1 / 3$ & $0 / 1$ & $1 / 1$ & - \\
\hline Depressed nasal bridge & $2 / 2$ & $4 / 5$ & $2 / 3$ & $1 / 1$ & $2 / 6$ & $5 / 16$ & $1 / 3$ & $0 / 1$ & $1 / 1$ & - \\
\hline Macroglossia & $1 / 2$ & $3 / 5$ & $0 / 3$ & $1 / 1$ & $2 / 6$ & $3 / 16$ & $1 / 3$ & $0 / 1$ & $1 / 1$ & - \\
\hline Microretrognathia & $2 / 2$ & $5 / 5$ & $0 / 3$ & $1 / 1$ & $5 / 6$ & $4 / 16$ & $0 / 3$ & $0 / 1$ & $0 / 1$ & - \\
\hline Low set ears & $2 / 2$ & $5 / 5$ & $2 / 3$ & $1 / 1$ & $4 / 6$ & $10 / 16$ & $1 / 3$ & $0 / 1$ & $0 / 1$ & - \\
\hline Large ears & $0 / 2$ & $1 / 5$ & $3 / 3$ & $1 / 1$ & $0 / 6$ & $1 / 16$ & $2 / 3$ & $1 / 1$ & $1 / 1$ & - \\
\hline Malformed ears & $2 / 2$ & $5 / 5$ & $1 / 3$ & $1 / 1$ & $5 / 6$ & $7 / 16$ & $3 / 3$ & $1 / 1$ & $1 / 1$ & - \\
\hline Short neck & $2 / 2$ & $4 / 5$ & $1 / 3$ & $1 / 1$ & $3 / 6$ & $3 / 16$ & $1 / 3$ & $0 / 1$ & $1 / 1$ & - \\
\hline Single crease & $0 / 2$ & $2 / 5$ & $1 / 3$ & $0 / 1$ & $3 / 6$ & $7 / 16$ & $2 / 4$ & $0 / 1$ & $1 / 1$ & - \\
\hline Kyphoscoliosis & $0 / 2$ & $1 / 5$ & $0 / 3$ & $1 / 1$ & $1 / 6$ & $6 / 16$ & $0 / 3$ & $0 / 1$ & $0 / 1$ & - \\
\hline Skeletal anomalies & $0 / 2$ & $1 / 5$ & $0 / 3$ & $1 / 1$ & $5 / 6$ & $13 / 16$ & $0 / 3$ & $0 / 1$ & $0 / 1$ & - \\
\hline Hip dislocation & $0 / 2$ & $2 / 5$ & $0 / 3$ & $1 / 1$ & $1 / 6$ & $5 / 16$ & $0 / 3$ & $0 / 1$ & $0 / 1$ & - \\
\hline Cleft palate & $1 / 2$ & $3 / 5$ & $0 / 3$ & $0 / 1$ & $6 / 6$ & $1 / 16$ & $0 / 4$ & $0 / 1$ & $0 / 1$ & - \\
\hline Congenital heart defects & $0 / 2$ & $1 / 5$ & $0 / 3$ & $0 / 1$ & $3 / 6$ & $4 / 16$ & $3 / 4$ & $1 / 1$ & $1 / 1$ & - \\
\hline Cerebral malformations & $1 / 2$ & $1 / 5$ & $2 / 3$ & $0 / 1$ & $3 / 6$ & 316 & $1 / 4$ & $0 / 1$ & $1 / 1$ & - \\
\hline Visceral malformations & NR & $0 / 5$ & $0 / 3$ & NR & $3 / 6$ & $4 / 16$ & $0 / 4$ & NR & NR & - \\
\hline Genital malformations & NR & $1 / 5$ & $0 / 3$ & NR & $2 / 6$ & $1 / 16$ & $1 / 4$ & NR & NR & - \\
\hline Cases & 2 & 5 & 3 & 1 & 6 & 16 & 4 & 1 & 1 & 1 \\
\hline
\end{tabular}

${ }^{*}$ Modified from Forabosco et al. ${ }^{2}$

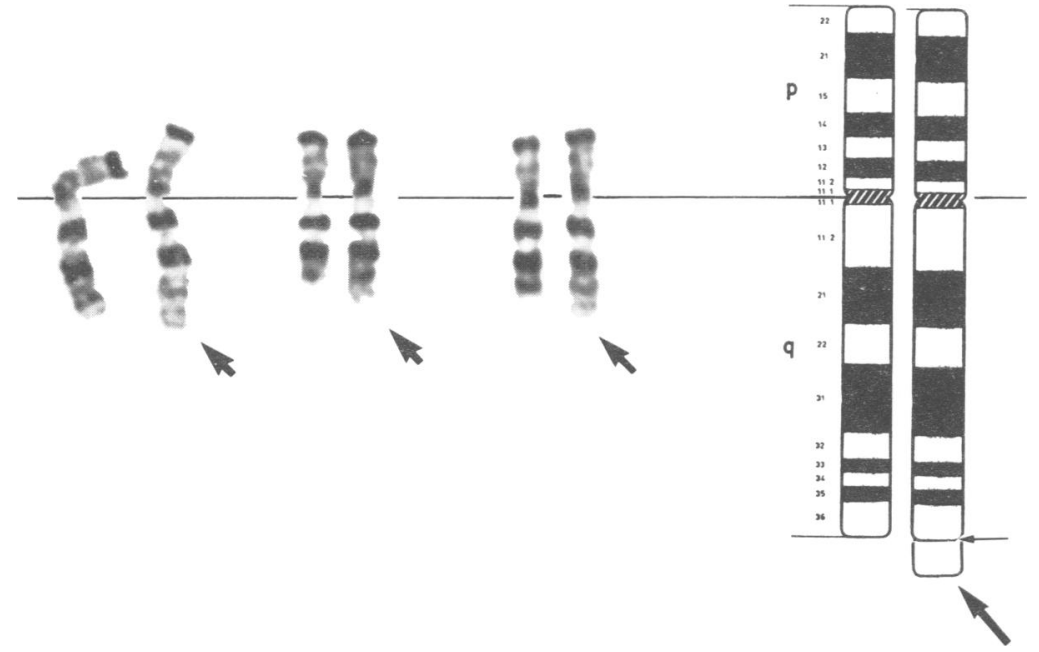

GTG banded partial karyotype of the proband. The abnormal chromosome 7 is marked by arrows and in addition a diagrammatic representation of dir dup $7 q 36 \rightarrow$ qter is shown (see text). the smallest duplication observed. The dysmorphic features observed in the present case may be correlated with a single band duplication. However, this should not imply that future cases with similar chromosomal abnormalities will have identical clinical consequences.

We wish to thank Michael Lazar for technical assistance and Sonia Jordan-Williams for typing this manuscript.

1 Vogel W. Partial duplication 7q. In: Yunis J, ed. New chromosomal syndromes. New York: Academic Press,

2 Forabosco A, Baroncini A, Dalpra L, et al. The phenotype of partial dup $(7 \mathrm{q})$ reconsidered: a report of five new cases. Clin Genet 1988;34:48-59.

3 Novales MA, Fernandez-Novoa C, Hevia A, San Martin V, Galera H. Partial trisomy for the long arm of chromosome 7. Case report and review. Hum Genet 1982;62:378-81.

4 Yunis E, Ramirez E, Uribe JG. Full trisomy 7 and Potter syndrome. Hum Genet 1980;54:13-8.

5 Bartsch O, Kalbe U, Ngo TKN, Lettau R, Schwinger E. Clinical diagnosis of partial duplication of $7 \mathrm{q} . A m \mathcal{F ~ M e d}$ Genet 1990;37:254-7. 